\title{
EVALUATION OF TENDON TRANSFER FOR RADIAL NERVE PALSY
}

\author{
Ibrahim A Dawood ${ }^{1}$; Mady A Abd Al-moktader ${ }^{2}$ MD; Mohammed M Fareed ${ }^{2}$ MD
}

\author{
* Corresponding Author: \\ Ibrahim dawood \\ dribrahimdwd@gmail.com
}

Received for publication March 2, 2020; Accepted September 4, 2020; Published online September 4, 2020.

Copyright 2020 The Authors published by Al-Azhar University, Faculty of Medicine, Cairo, Egypt. All rights reserved. This an open-access article distributed under the legal terms, where it is permissible to download and share the work provided it is properly cited. The work cannot be changed in any way or used commercially.

doi:10.21608/aimj.2020.24985.1158

${ }^{l}$ Ministry of Health Hospitals.

${ }^{2}$ Plastic and burn surgery department, Faculty of Medicine, AlAzhar University, Cairo..

\begin{abstract}
Background: Radial nerve palsy had disabling effect on hand function, leads to loss of power grip due to lost extension. Many surgical procedure was described to restoring function, tendon transfer is an important option due to bad reputation of nerve repair. The donor site from muscle supplied by the median and ulnar nerves.
\end{abstract}

Aim of work: Evaluation of different methods of tendon transfer for management of wrist and finger drop in radial or PIN palsy.

Patient and Methods: 20 patients with radial or PIN palsy. Presented with post traumatic injury, 14cases in the arm with total radial nerve, 6cases in forearm with PIN. Various techniques of tendon transfer were used including FCU transfer, FCR transfer, and FDS transfer to the EDC. In cases with high radial injury, PT to ECRB transfered to restore wrist extension and palmaris for thumb extension.

Results: This study included 20patients in three groups, the FCR group including 9patients, the FCU group including 6patients, and the FDS group including 5patients. In FCR group, 6patients $(66.6 \%)$ were excellent, 2patients(22.2\%) were good and 1patient(11.1\%) was fair. In FCU group, 3 patients $(50 \%)$ were excellent, 2patients $(33.3 \%)$ were good and 1patient(16.7\%) was fair. In FDS group, 3patients(60\%) were excellent, 1 patient $(20 \%)$ was good and 1patient(20\%) was fair according to an objective evaluation.

Conclusion: The tendon transfer is a very successful treatment for irreversible radial nerve paralysis, many techniques of tendon transfer were prescribed for treatment of wrist and finger drop. The FCR transfer is the best option for restoration of hand extension Because it preserves the important moment of flexion and ulnar deviation of the wrist which is important for power grip in working men and it's transfer is easier, quicker and associated with less intra-operative dissection and less donor site morbidity.

Keywords: Tendon transfer; Radial nerve injury; PIN injury.

Disclosure: The authors have no financial interest to declare in relation to the content of this article. The Article Processing Charge was paid for by the authors.

Authorship: All authors have a substantial contribution to the article.

\section{INTRODUCTION}

Loss of radial nerve function in the hand have asignificant disability. The patient cannot extend the fingers and thumb, so has a great difficulty in grasping objects. $^{1}$

Surgical methods for treatment of radial nerve lesions, are direct nerve repair, nerve graft and nerve or tendon transfer. $^{2}$
Tendon transfer in patients with radial nerve palsy have good results once nerve repair has failed. When no improvement in radial nerve lesions is noticed within one-year interval, tendon transfer is indicated. ${ }^{3}$

The motor units available for transfer for patients with isolated radial nerve palsy include all extrinsic muscles innervated by median and ulnar nerves. This multitude of available motors provides the surgeon with almost limitless number of possible combinations for transfers. However, one or two 
combinations of transfers are used by majority of surgeons in most instances. ${ }^{4}$

The aim of this study is to evaluate Different Modalities of tendon transfer to reconstruct the hand function in Patients who suffer from failure of neural recovery following conservative or surgical repair of radial nerve or PIN palsy to restore active wrist and fingers extension.

\section{PATIENT AND METHOD}

Perspective study included 20 patients, with radial nerve or PIN lesions with either failed repair, or during primary repair as internal splint, and conducted at Plastic surgery department, faculty of medicine- AlAzhar university, from January2018 to October2019 after approval of Ethical committee of Al- Azhar University hospitals.

20 Patients presented with wrist and fingers drop following high or low radial nerve palsy, PT for ECRB and Palmaris for EPL was used as routine, patients divided into three groups according to tendon transfer for restoration of EDC: The FCR group including 9patients and selected to preserve FCU which is important wrist flexor and only remaining ulnar deviator which is critical dart throwing and important for power grip in working man and Removing the FCU from the wrist will aggravate radial deviation particularly in patients with PIN palsy who have normally functioning strong ECRL. the FCU group including 6patients and selected according to surgeon preference and if patients have preoperative ulnar deviation, and the FDS group including 5patients and selected according to absence of PL for thumb reconstruction and also In patient with fused wrist who cannot employ the tenodesis effect.

Data were analyzed using Statistical Program for Social Science(SPSS)version15.0. Quantitative data were expressed as mean \pm standard deviation(SD).Qualitative data were expressed as frequency and percentage.

The following tests were done:

A one-way analysis of variance(ANOVA):when comparing between more than two means.

Chi-square test: was used when comparing between non-parametric data.

Probability(P-value)

P-value $<0.05$ was considered significant.

$\mathrm{P}$-value $<0.001$ was considered as highly significant.

P-value > 0.05 was considered insignificant.

The mean age of the patients in FCR group is $33.4 \pm 8.8$, FCU group is $38.8 \pm 11.4$ and FDS group is $37.4 \pm 11.3$ years. 13patients $(65 \%)$ male and 7 females $(35 \%)$, 14 patients $(70 \%)$ have nerve injury at dominant and 6patients(30\%) at non-dominant.
Patient evaluation: preoperative assessment included: mobile joints, good soft tissue coverage and good functioning donor muscles included PT,FCR,FCU,FDS and PL. Investigations in form of; plain X-ray, nerve conduction study, EMG, measurement of ROM, examination of motor power and grip, evaluation of donor muscles, and medical photography.

\section{Operative technique}

Under general or brachial block anesthesia, supine position, tourniquet, magnification, Sterilization and toweling.

Wrist extension, restored by transferring PT to ECRB with high radial palsy Figure (1).

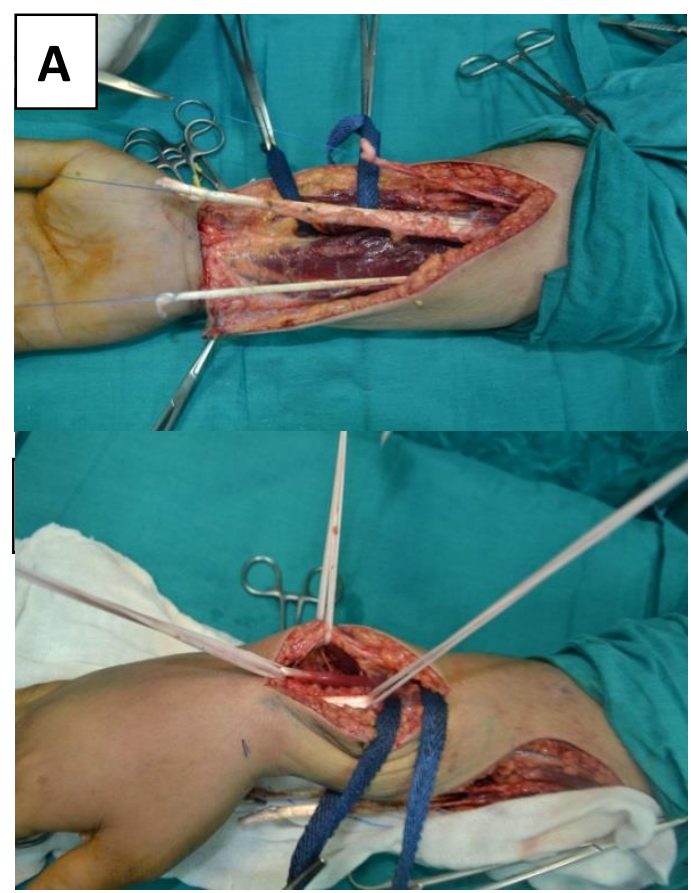

Figure 1: (A) PT harvested with periosteal extension, (B) ECRB is identified and sutured to PT to restore wrist extension.

FCR Group: FCR transferred to EDC to restore fingers extension and PL transferred to restore thumb extention and abduction. Brand's transfer Figure (2). 

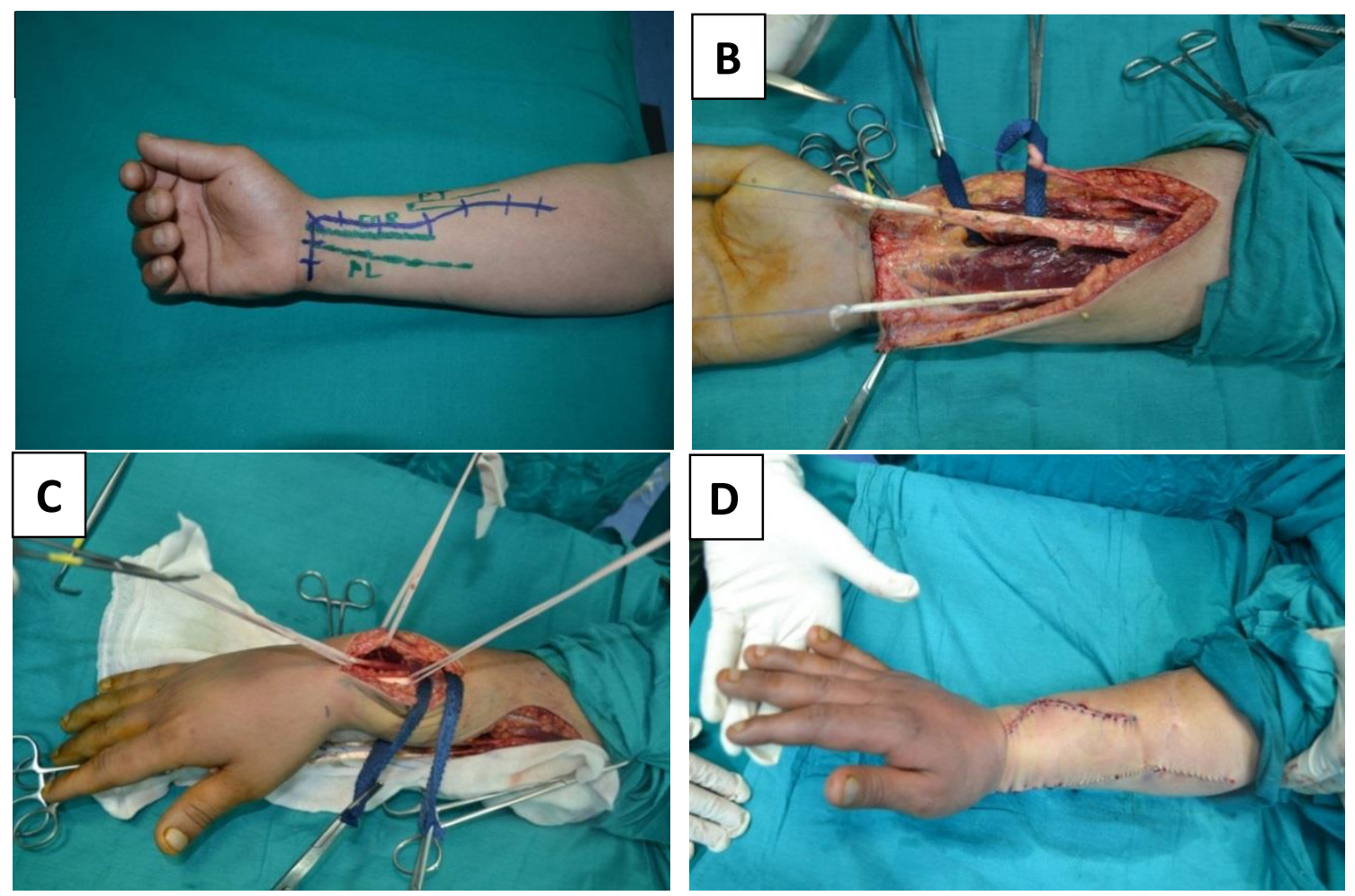

Figure 2: BRAND TRANSFER(A)preoperative marking of incision, (B) FCR, PT and PL tendons are harvested for transfer, (C) ECRB , EPL and EDC identified through dorsal incision, (D) the wound closed after A Pulvertaft weave of PL to EPL end to end to restore thumb extention and FCR to EDC to restore fingers extention.

FCU group: FCU was used to restore fingers extension and PL transferred to restore thumb extention and abduction Jone's transfer Figure (3).

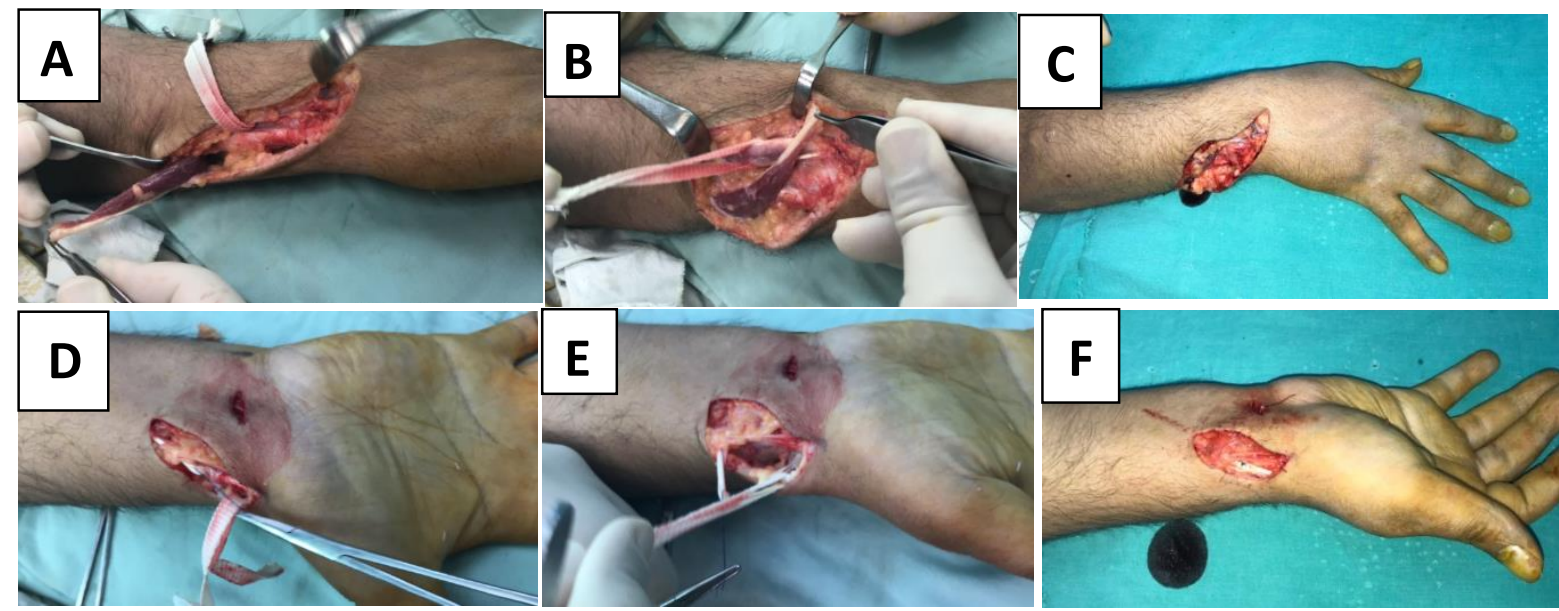

Figure 3: JONES TRANSFER (A)FCU harvested for transfer,(B)FCU transferd through SC tunnel on the ulnar border of the wrist,(C)Pulvertaft weave of FCU to EDC end to end to restore fingers extention,(D)PL harvested for transfer,(E)EPL identified and released from third compartment,(F)A Pulvertaft weave of PL to EPL end to end to restore thumb extention. 
FDS group: FDS of middle and ring fingers was used for thumb and fingers extension extension respectively.Boye's transfer Figure (4)
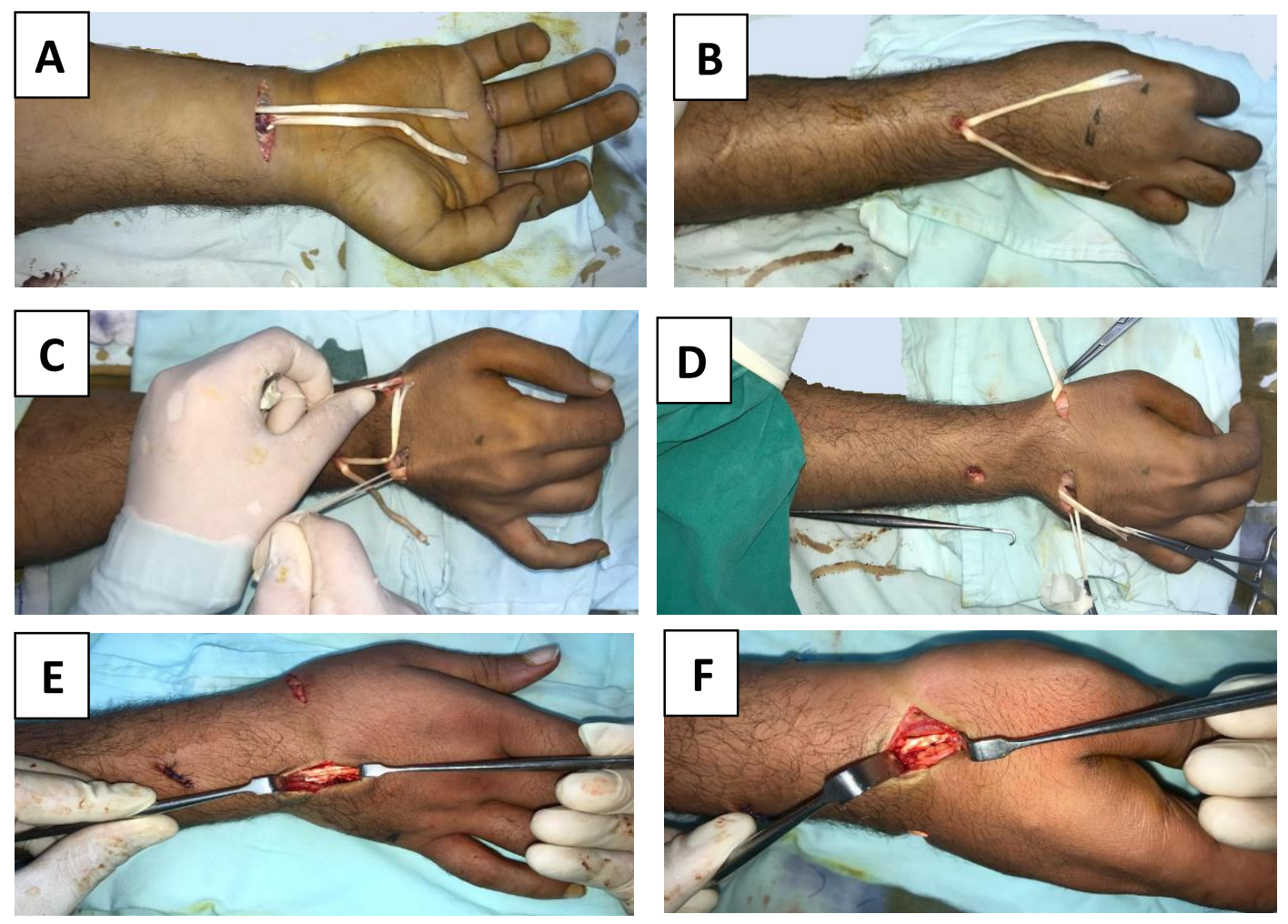

Figure 4: BOYES TRANSFER (A)The FDS tendons of ring\&middle fingers are harvested for transfer,(B)The FDS tendons of ring \&middle fingers are transferred dorsally through interosseous tunnel,(C)EDC and EPL tendons are identified,(D)The FDS tendons of ring \&middle fingers are transferred through SC tunnel to EDC and EPL respectively,(E) A Pulvertaft weave of FDS tendon of ring finger to EDC to restore fingers extention,(F) A Pulvertaft weave of FDS tendon of middle finger to EPL end to side to restore thumb extention.

Protective thermoplastic slab/splint used as soon as surgery was over, before waking up the patient from general anaesthesia. The elbow should be flexed at 90degrees, the forearm pronated at 15-30degrees, the wrist was immobilized in $40^{\circ}$ of extension, the MCP joints in $10^{\circ}$ of hyperextension and the thumb in maximum extension and abduction using forearm splint. The PIP and DIP joints of the fingers were left free.

\section{Postoperative Care and Rehabilitation}

Patients were discharged one day postoperative, Sutures removed 10-15days and splint removed 46 weeks post operatively. The patients started physiotherapy program 3 weeks postoperatively for reeducation of the muscle. Follow-up weekly for first 2 months then monthly up to 6months.

Postoperative ROM of wrist and fingers measured by goniometer(Fig.5) and recorded(Table .1) and subjective evaluation also performed and recorded Table (2). 


\begin{tabular}{|c|c|c|c|c|}
\hline & Excellent & Good & Fair & Poor \\
\hline Wrist extension & $0-80^{\circ}$ & $0^{\circ}$ & $45^{\circ}$ extension lag & $70^{\circ}$ extension lag \\
\hline Fingers' extension & $0-10^{\circ}$ & $0^{\circ}$ & $45^{\circ}$ extension lag & $90^{\circ}$ extension lag \\
\hline $\begin{array}{l}\text { Thumb abduction } \\
\text { and extension }\end{array}$ & $80-100^{\circ}$ & $60-80^{\circ}$ & $30-60^{\circ}$ & $0-30^{\circ}$ \\
\hline Wrist flexion & Full & $0-20^{\circ}$ & $0^{\circ}$ & dorsiflexion \\
\hline
\end{tabular}

Table 1: Objective evaluation; Criteria for range of motion of wrist,thumb, and fingers.

\begin{tabular}{|l|l|l|}
\hline $\mathbf{0}$ & Not improved in comparison to pre-operative state. & Poor \\
\hline $\mathbf{1}$ & Slightly improved; does not help in everyday activities. & Fair \\
\hline $\mathbf{2}$ & Slightly improved; helps in everyday activities, but cannot tolerate work load. & Good \\
\hline $\mathbf{3}$ & Moderately improved; can be burdened with work load for1-2hours. & Good \\
\hline $\mathbf{4}$ & Greatly improved; can be burdened with work load for more than2hours. & Excellent \\
\hline $\mathbf{5}$ & $\begin{array}{l}\text { Greatly improved; uses hand normally in all muscular activities with usual } \\
\text { intensity. }\end{array}$ & Excellent \\
\hline
\end{tabular}

Table 2: Subjective evaluation scale.

Results

This study included 20patients. The mean age of patients in FCR group is $33.4 \pm 8.8$,FCU group is $38.8 \pm 11.4$ and FDS group is $37.4 \pm 11.3$ years(p-value $=0.58)$ Table (3). There were5(55.6\%)male and 4(44.4\%)in FCR group, 4(66.7\%)males and $2(33.3 \%)$ females in FCU group and 4(80\%)males and $1(20 \%)$ female in FDS group $(\mathrm{p}$-value $=0.65)$ Table (4). 7patients(77.8\%)dominant and 2patients(22.2\%)non dominant in FCR group, 3 patients $(50 \%)$ dominant and 3patients $(50 \%)$ non dominant in FCU group while there were 4patients(80\%)dominant and 1 patient $(20 \%)$ non dominant in FDS group (p-value 0.44) Table (5).

\begin{tabular}{|c|c|c|c|c|c|}
\hline Variables & \multicolumn{2}{|c|}{$\begin{array}{c}\text { FCR } \\
\text { Group } \\
(\mathrm{N}=9)\end{array}$} & $\begin{array}{l}\text { FCU } \\
\text { Group } \\
(\mathbf{N}=6)\end{array}$ & $\begin{array}{l}\text { FDS } \\
\text { Group } \\
(\mathbf{N}=5)\end{array}$ & $\begin{array}{c}P \text { - } \\
\text { value }\end{array}$ \\
\hline \multirow[t]{2}{*}{ Age(years) } & Mean & 33.4 & 38.8 & 37.4 & \multirow[t]{2}{*}{0.58} \\
\hline & \pm SD & 8.8 & 11.4 & 11.3 & \\
\hline
\end{tabular}

Table 3: Comparison between studied groups as regard age.

\begin{tabular}{|c|c|c|c|c|c|}
\multicolumn{2}{|c|}{ Variables } & $\begin{array}{c}\text { FCR } \\
\text { Group } \\
(\mathbf{N}=9)\end{array}$ & $\begin{array}{c}\text { FCU } \\
\text { Group } \\
(\mathbf{N}=6)\end{array}$ & $\begin{array}{c}\text { FDS } \\
\text { Group } \\
(\mathbf{N}=5)\end{array}$ & $\begin{array}{c}\text { P- } \\
\text { val } \\
\text { ue }\end{array}$ \\
\hline \multirow{2}{*}{ Sex } & Male & $5(55.6 \%)$ & $4(66.7 \%)$ & $4(80 \%)$ & 0.6 \\
\cline { 2 - 6 } & Female & $4(44.4 \%)$ & $2(33.3 \%)$ & $1(20 \%)$ & 5 \\
\hline
\end{tabular}

Table 4: Comparison between studied groups as regard sex.

\begin{tabular}{|c|c|c|c|c|c|}
\hline \multicolumn{2}{|c|}{ Variables } & $\begin{array}{c}\text { FCR } \\
\text { Group } \\
(\mathbf{N}=9)\end{array}$ & $\begin{array}{c}\text { FCU } \\
\text { Group } \\
(\mathbf{N}=6)\end{array}$ & $\begin{array}{l}\text { FDS } \\
\text { Group } \\
(\mathbf{N}=5)\end{array}$ & $\begin{array}{c}P- \\
\text { value }\end{array}$ \\
\hline \multirow[t]{2}{*}{ Sex } & Male & $5(55.6 \%)$ & $4(66.7 \%)$ & $4(80 \%)$ & \multirow[t]{2}{*}{0.65} \\
\hline & Female & $4(44.4 \%)$ & $2(33.3 \%)$ & $1(20 \%)$ & \\
\hline
\end{tabular}

Table 4: Comparison between studied groups as regard sex.

\begin{tabular}{|c|c|c|c|c|c|}
\hline & Variables & $\begin{array}{c}\text { FCR } \\
\text { Group } \\
(\mathbf{N}=9)\end{array}$ & $\begin{array}{c}\text { FCU } \\
\text { Group } \\
(\mathbf{N}=6)\end{array}$ & $\begin{array}{c}\text { FDS } \\
\text { Group } \\
(\mathrm{N}=5)\end{array}$ & $\begin{array}{c}\text { P- } \\
\text { value }\end{array}$ \\
\hline \multirow[t]{2}{*}{ Side } & Dominant & $7(77.8 \%)$ & $3(50 \%)$ & $4(80 \%)$ & \multirow[t]{2}{*}{0.44} \\
\hline & $\begin{array}{l}\text { Non } \\
\text { Dominant }\end{array}$ & $2(22.2 \%)$ & $3(50 \%)$ & $1(20 \%)$ & \\
\hline
\end{tabular}

Table 5: Comparison between studied groups as regard side.

The wounds healed with first intention with no problems except 2 case in group 1,1 cases in group2and treated with frequent dressing and healed by secondary intention with no major complications. Reeducation started one month postoperative and mean follow-up period was 9months, (range 6-12months).

In FCR group , 6 patients( $66.6 \%$ ) were excellent, 2 patients(22.2\%) were good and 1patient(11.1\%) was fair. 
In FCU group, 3 patients (50\%) were excellent, 2 patients $(33.3 \%)$ were good and 1 patient $(16.7 \%)$ was fair.

In FDS group , 3 patients (60\%) were excellent, 1 patient $(20 \%)$ was good and 1 patient $(20 \%)$ was fair. so there is no statistical significant difference in result(p-value > 0.05) between studied groups as regard objective Table (6) and subjective evaluation Table (7). but, regarding donor site morbidity, time of operation, some loss of grip strength, preservation of important moment of flexion and ulnar deviation of the wrist which is important for power grip in working men. easier, quicker and associated with less intraoperative dissection. we found that there is significant difference between the three groups in favor of FCR transfer.

\begin{tabular}{|c|c|c|c|c|c|}
\hline \multicolumn{2}{|l|}{ Variables } & $\begin{array}{c}\text { FCR } \\
\text { Group } \\
(\mathrm{N}=9)\end{array}$ & $\begin{array}{c}\text { FCU } \\
\text { Group } \\
(\mathrm{N}=6)\end{array}$ & $\begin{array}{c}\text { FDS } \\
\text { Group } \\
(\mathrm{N}=5)\end{array}$ & $\begin{array}{c}\text { P- } \\
\text { value }\end{array}$ \\
\hline \multirow[t]{3}{*}{$\begin{array}{l}\text { objective } \\
\text { evaluation }\end{array}$} & Fair & $\begin{array}{c}1 \\
11.1 \%\end{array}$ & $\begin{array}{c}1 \\
16.7 \%\end{array}$ & $\begin{array}{c}1 \\
20 \%\end{array}$ & \multirow[t]{3}{*}{0.96} \\
\hline & Good & $\begin{array}{c}2 \\
22.2 \%\end{array}$ & $\begin{array}{c}2 \\
33.3 \%\end{array}$ & $\begin{array}{c}1 \\
20 \%\end{array}$ & \\
\hline & Excellent & $\begin{array}{c}6 \\
66.6 \%\end{array}$ & $\begin{array}{c}3 \\
50 \%\end{array}$ & $\begin{array}{c}3 \\
60 \%\end{array}$ & \\
\hline
\end{tabular}

Table 6: Comparison between studied groups as regard objective evaluation.

\begin{tabular}{|c|c|c|c|c|c|}
\hline \multicolumn{2}{|c|}{ Variables } & $\begin{array}{c}\text { FCR } \\
\text { Group } \\
(\mathbf{N}=9)\end{array}$ & $\begin{array}{c}\text { FCU } \\
\text { Group } \\
(\mathrm{N}=6)\end{array}$ & $\begin{array}{c}\text { FDS } \\
\text { Group } \\
(\mathbf{N}=5)\end{array}$ & $\begin{array}{c}\text { P- } \\
\text { value }\end{array}$ \\
\hline \multirow{2}{*}{$\begin{array}{l}\text { Subjective } \\
\text { evaluation }\end{array}$} & Mean & 3.8 & 4.0 & 3.6 & \multirow[t]{2}{*}{0.8} \\
\hline & \pm SD & 0.9 & 0.9 & 1.1 & \\
\hline
\end{tabular}

Table 7: Comparison between studied groups as regard subjective evaluation.

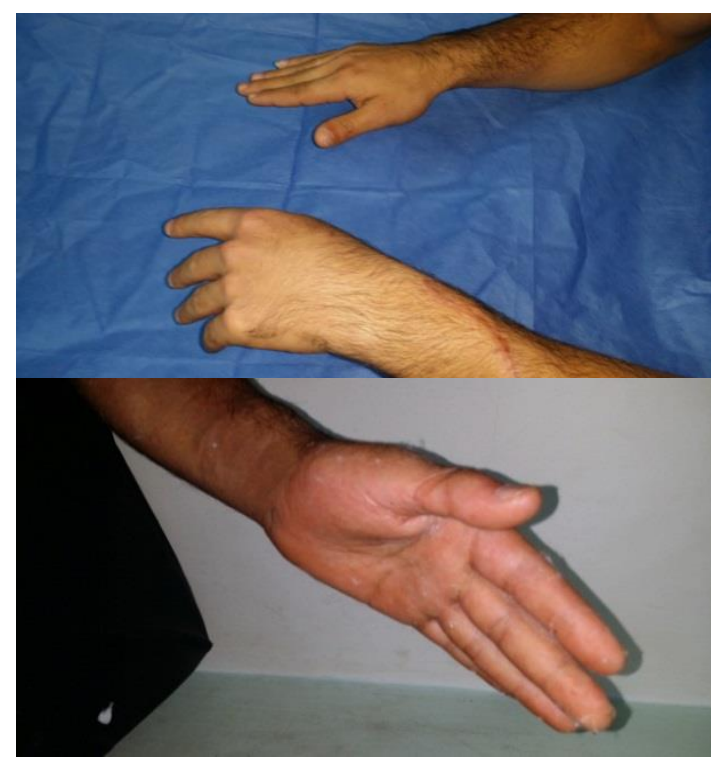

Figure 6: pre\&post-operative result with restoration of fingers and thumb extension by FCR and PL transfer respectively 1month later.
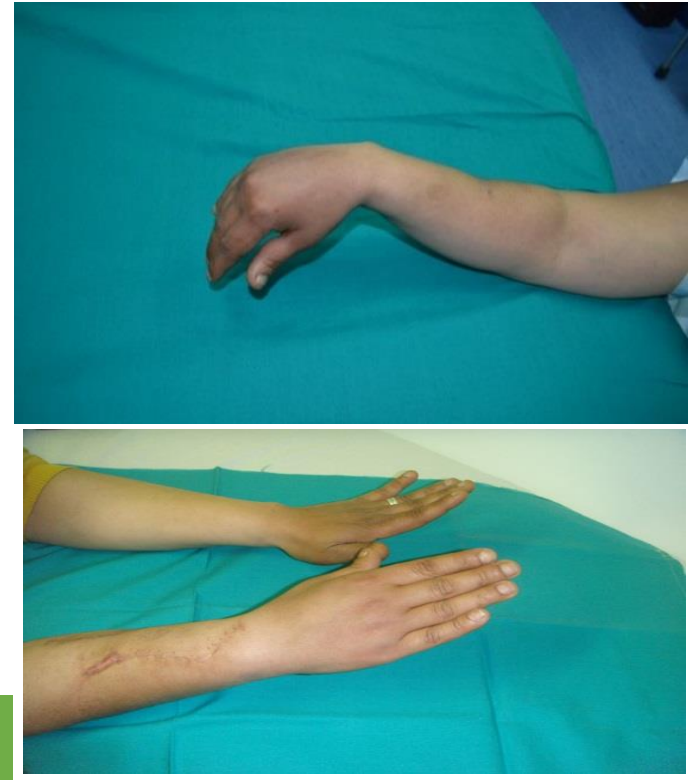

Figure 7: pre \& post-operative result with restoration of wrist, fingers and thumb extension by PT, FCR and PL transfer respectively 6month later.

\section{DISCUSSION}

The radial nerve is the most frequently injured major nerve in the upper limb and etiology of its injury is quite varied, As result of its proximity to humeral shaft, as well as its long and tortuous course. ${ }^{7}$

Most authors believe that tendon transfers will result in good outcomes in cases of radial nerve palsy with irreparable damage or reconstruction failure. $^{2}$

Sunderland recommended that one year is enough to go on tendon transfer if nerve recovery has not happened in this time. ${ }^{8}$

Burkhalter believed that the greatest functional loss in patient with radial nerve injury is weakness in grip and recommended early transfer to eliminate the need for external splint and reduce the period of disability after injury. ${ }^{9}$

There is no consensus on the best method for tendon transfer in patients with radial nerve palsy. ${ }^{10}$

Classically,surgeons use different combinations of tendon transfers in order to achieve three major goals in treatment of radial nerve palsy including restoration of finger extension, restoration of thumb and wrist extension in cases of severe radial nerve palsy. ${ }^{6}$

.In early transfer, This was intended as substitute for internal splint during regeneration of the nerve after repair and there are quite acceptable functional results in first weeks after removing plaster splint and patients 
were able to return to work early than expected before nerve healing and regeneration had happened. ${ }^{11}$

The rationale for Jones transfer(FCU to EDC)was amatter of surgeon's preference and some patients have ulnar deviation of the wrist pre-operatively while Brands(FCR to EDC)transfer was advocated instead of FCU to restore finger extension to preserve FCU which is more important wrist flexor than FCR because normal axis of wrist motion is from dorsalradial to volar-ulnar. ${ }^{12}$

Boyes then Chuinard et al;suggested that superficialis tendons, with their greater excursion $(70 \mathrm{~mm})$, would be better motors for finger and wrist extensors. Their major proof was the fact that amplitude of action and power of wrist flexors is too small to allow simultaneous extension of wrist and fingers. ${ }^{13}$

The FDS transfer was primarily employed as it provides thumb extension independent from wrist and fingers extension, because the FDS control each finger is independent from other fingers. The FDS of the middle finger was preferred as motor for EPL because it provides $7 \mathrm{~cm}$ of excursion, while FCR provides only $3 \mathrm{~cm}$; therefore, the FDS is more efficient, noting that EPL normally provides $5 \mathrm{~cm}$ excursion. ${ }^{14}$

In this study, Significant improvements in wrist and finger extension and hand grip were obtained. These due to good rehabilitation program and optimal intraoperative tensioning of donor tendon to recipient extensor tendon. Re-education of muscle-tendon unit is important part of rehabilitation following tendon transfers.Surgeon and hand therapist should implement patient integrated team approach to improve functional outcome.Following one-month postsurgical splinting and physiotherapy, ranges of motion in MCP,PIP andDIP joints of the fingers were compared between all patients.

The results of statistical analysis showed no significant difference in ranges of motion in respective joints between them. but,regarding the donor site morbidity, the time of operation, some loss of grip strength, preservation of important moment of flexion and ulnar deviation of wrist which is important for power grip in aworking men. easier, quicker and associated with less intra-operative dissection. we found that there is significant difference between three groups in favor of FCR transfer.

As the PTwas used in most patient groups, probably it may be concluded that the most successful result in radial nerve paralysis treatment by tendon transfers will be wrist extension. Limitation of wrist flexion was noted in most of our patients, though actually none had any complaints of it. This must be due to the fact that less wrist flexion is necessary than extension in daily activities and fewer activities need it. We did not measure the power of grip because of lack of equipment. Though surely this is alimitation of the study,it may be considered that power of grip differs among individuals, and even between the two hands in the same individual, both sides cannot be of equal strength,so grip is not a good parameter for comparison.

The fact that none of our patients had any complaints of a reduced power of grip may be due to their accommodation to procedure or to improvement in grip strength. There is concern about loss of some functions in the hand and wrist after transfer of three tendons. However, some authors believe that a single FCU cannot provide simultaneous wrist dorsiflexion and fingers extension.

\section{CONCLUSION}

The tendon transfer is avery successful treatment for irreversible radial nerve paralysis, and result in good functional outcome of wrist and finger extension and power of hand grip. We recommend early transfer at time of nerve repair.Because early transfer reduce the period of disability after injury to weeks rather than months after nerve repair. We also recommend FCR transfer Because it preserves the important moment of flexion and ulnar deviation of the wrist which is important for power grip in aworking men. Harvest of FCU removes the only remaining ulnar deviator of wrist, resulting in radial deviation, particularly in patients with PIN palsy,the FCR transfer is easier, quicker and associated with less intra-operative dissection.

\section{REFERENCES}

1. Labosky DA and Waggy CA: Apparent weakness of median and ulnar motors in radial nerve palsy, Am J Hand Surg. 1986;11;P:528-533.

2. Lowe J, Sen B, Subhro K and Mackinnon SE: Current Approach to Radial Nerve Paralysis. Plast Reconstr Surg. 2002;110;P:1099-1113.

3. Sammer DM and Chung KC :Tendon Transfers:Part I Principles of Transfer and Transfers for Radial Nerve Palsy. Plast Reconstr Surg. 2009;123(5);P:169-177.

4. Davis TRC: Principles of Tendon Transfers of Median, Radial, and Ulnar Nerves. In:wolfe SW, Hotchkiss RN, Pederson WC, Kozin SH and Cohen MS(Eds). Green's operative hand surgery.7th ed.Vol.(2). Philadelphia: Elsevier.2016; P:10321077.

5. Moussavi AA, Saied A and Karbalaeikhani A: Outcome of tendon transfer for radial nerve paralysis:Comparison of three methods. Indian $J$ Orthop Surg. 2011;45;P:558-562.

6. Krishnan KG, Schackert G: An analysis of results after selective tendon transfers through the interosseous membrane to provide selective finger and thumb extension in chronic irreparable radial nerve lesions. Am J Hand Surg. 2008;33;P:223-231.

7. Jobe MT and Martiney SF: Peripheral nerve injuries.In:Campbell's operative orthopaedics.12th 
ed. Philadelphia: Elsevier Mosby. 2013;P:30633123.

8. Sunderland S: Decision making in clinical management of nerve injury and repair.In:Sunderland $S$,(ed).Nerve Injuries and Their Repair. Edinburgh:Churchill Livingstone. 1991;P:413-31.

9. Burkhalter WE: Early tendon transfer in upper extremity peripheral nerve injury.Clinical Orthopaedics and Related Research. 1974;104;P:68-79.

10. Yavari M, Abdolrazaghi HA and Riahi A: Comparative Study on Tendon Transfer Surgery in Patients with Radial Nerve Palsy.World J Plast Surg.2014;3(1);P:47-51.

11. Gousheh J and Arasteh E: Transfer of asingle flexor carpi ulnaris tendon for treatment of radial nerve palsy. Br J Hand Surg. 2006;31;P:542-546.

12. Dunnet WJ, Housden PL and Birch R: Flexor to extensor tendon transfers in the hand. $\mathrm{Br} J$ Hand Surg. 1995;20;P:26-28.

13. Chuinard RG, Boyes JH, Stark HH and Ashworth CR: Tendon transfers for radial nerve palsy: use of superficialis tendons for digital extension. Am J Hand Surg. 1978;3;P:560-70.

14. Jones NF and Khiabani KT: Tendon transfers in the upper limb. In: Mathes ST and Hentz VR(Eds):Plastic surgery; 2nd ed; Philadelphia; Saunders;Vol8. 2006;P:453-487. 